\title{
Development and Validation of a Novel Generic Health- related Quality of Life Instrument With 20 Items (HINT-20)
}

\author{
Min-Woo Jo ${ }^{1 *}$, Hyeon-Jeong Lee ${ }^{1 *}$, Soo Young Kim², Seon-Ha Kim³ ${ }^{3}$ Hyejung Chang ${ }^{4}$, Jeonghoon Ahn ${ }^{5}$, Minsu Ock ${ }^{1}$ \\ ${ }^{1}$ Department of Preventive Medicine, University of Ulsan College of Medicine, Seoul; ${ }^{2}$ Department of Family Medicine, Kangdong Sacred Heart \\ Hospital, Hallym University College of Medicine, Seoul; ${ }^{3}$ Department of Nursing, Dankook University College of Nursing, Cheonan; ${ }^{4}$ Department of \\ Management, Kyung Hee University School of Management, Seoul; Department of Health Convergence, Ewha Womans University, Seoul, Korea
}

Objectives: Few attempts have been made to develop a generic health-related quality of life (HRQoL) instrument and to examine its validity and reliability in Korea. We aimed to do this in our present study.

Methods: After a literature review of existing generic HRQoL instruments, a focus group discussion, in-depth interviews, and expert consultations, we selected 30 tentative items for a new HRQoL measure. These items were evaluated by assessing their ceiling effects, difficulty, and redundancy in the first survey. To validate the HRQoL instrument that was developed, known-groups validity and convergent/discriminant validity were evaluated and its test-retest reliability was examined in the second survey.

Results: Of the 30 items originally assessed for the HRQoL instrument, four were excluded due to high ceiling effects and six were removed due to redundancy. We ultimately developed a HRQoL instrument with a reduced number of 20 items, known as the Healthrelated Quality of Life Instrument with 20 items (HINT-20), incorporating physical, mental, social, and positive health dimensions. The results of the HINT-20 for known-groups validity were poorer in women, the elderly, and those with a low income. For convergent/discriminant validity, the correlation coefficients of items (except vitality) in the physical health dimension with the physical component summary of the Short Form 36 version 2 (SF-36v2) were generally higher than the correlations of those items with the mental component summary of the SF-36v2, and vice versa. Regarding test-retest reliability, the intraclass correlation coefficient of the total HINT-20 score was $0.813(p<0.001)$.

Conclusions: A novel generic HRQoL instrument, the HINT-20, was developed for the Korean general population and showed acceptable validity and reliability.

Key words: Health-related quality of life, Questionnaire, Validation study

\section{INTRODUCTION}

Received: September 2, 2016, Accepted: December 23, 2016

Corresponding author: Min-Woo Jo, MD, PhD

88 Olympic-ro 43-gil, Songpa-gu, Seoul 05505, Korea

Tel: +82-2-3010- 4264, Fax: +82-2-477-2898

E-mail: mdjominwoo@gmail.com

*Jo and Lee contributed equally to this work as joint first authors.

This is an Open Access article distributed under the terms of the Creative Commons Attribution Non-Commercial License (http://creativecommons.org/licenses/by$\mathrm{nc} / 4.0 /$ ) which permits unrestricted non-commercial use, distribution, and reproduction in any medium, provided the original work is properly cited.
Measuring health-related quality of life (HRQoL) is important in both clinical practice and public health. Decreases in HRQoL have been found to be related to poorer health outcomes, as measured by hospital readmission and vital prognosis $[1,2]$. Cost-utility analysis, an economic evaluation method that considers HRQoL as an outcome, has been suggested as a standard approach in drug reimbursement processes and cancer screening programs [3,4]. In addition, many governments 
have stated that improving the quality of life of their citizens is a main policy target $[5,6]$.

HRQoL is characterized by multifactoriality and subjectivity [7]. Regarding multifactoriality, physical, psychological, and societal dimensions can be measured at several levels to determine HRQoL [8]. Based on the theory of functionalism [9], many researchers have argued that people with good HRQoL show no problems in various HRQoL dimensions and/or can perform certain functions well. In contrast, others have argued that HRQoL should include positive well-being [8], as has been suggested by the World Health Organization (WHO) as part of the definition of health [10]. Generally, HRQoL has been measured through questionnaire-style surveys, which may result in subjective measurements of health. More than 900 questionnaires have been developed for this purpose and registered in a single international patient-reported outcome and HRQoL instrument database [11]. More than 100 generic instruments have been developed to assess HRQoL, such as the Short Form 36 version 2 (SF-36V2) and the WHO Quality of Life (WHOQOL) instrument, but these questionnaires, although used internationally, were developed in Western countries.

Several pieces of evidence suggest that cultural differences in HRQoL may exist [12]. For example, Japanese people report problems in certain dimensions less frequently than others [13]. In the EuroQol-5D (EQ-5D), Japanese gave lower scores than Europeans on the EuroQol visual analog scale (VAS), but reported fewer problems in the dimensions of usual activities, pain/discomfort, and anxiety/depression. The relatively low VAS scores may have stemmed not only from real differences in health status, but also from cultural differences. In Korea, similar findings regarding those dimensions have been reported [14]. These results may reflect real differences in health status across countries, but may also be indicative of cultural differences. Cultural differences may lead to different perceptions of health state descriptions when HRQoL instrument questionnaires are presented using text [15].

In addition, the psychometric properties of the SF-36v2 and Short Form 12 version 2 (SF-12v2) in Korea are somewhat different from those observed in some Western countries. The SF$36 \mathrm{v} 2$ scales for vitality, mental health $(\mathrm{MH})$, and social functioning showed poorer results for item discriminant validity [16]. The role physical and role emotional scales were loaded onto the same factor in the SF-36v2, and this pattern also appeared in factor analysis of the SF-12v2 in Korea $[16,17]$.

However, to our best knowledge, few attempts have been made to develop generic HRQoL instruments for use in Asian countries. A previous study from China used a modified version of the WHOQOL-100 and the SF-36V2 [18], and another from Japan attempted to develop a HRQoL instrument [19]. In Korea, two instruments have been developed previously. Kim et al. [20] developed a HRQoL instrument consisting of 46 items, the Korean Health-related Quality of Life Scale, by surveying ambulatory care patients, collecting their symptom descriptions, and categorizing them into domains, followed by validity and reliability testing in patients. However, the psychometric properties of this instrument were not evaluated in the general population. The other HRQoL instrument, with 44 items, likewise did not undergo validity and reliability testing in the Korean general population [21]. They have not been often used, even in Korea, for several reasons, including the fact that they include numerous measurement items and have not been published in other languages.

In the present study, we aimed to develop a novel generic HRQoL instrument, the Health-related Quality of Life Instrument with 20 items (HINT-20), and to examine its validity and reliability in the Korean general population.

\section{METHODS}

\section{Literature Review and Item Generation}

We first undertook a review of the literature related to the concept and definition of HRQoL and existing instruments, in order to identify $\mathrm{HRQ}$ oL dimensions and items. For this purpose, we used search engines such as PubMed, Korean Medical Database and KoreaMed with terms such as "HRQoL," "HRQoL tool," "HRQoL instrument development," "general population", and so on. We defined four dimensions (physical, social, mental, and positive health dimension) based on the concepts of functionalism and positive well-being $[8,9]$. Simultaneously, we used the PRoQolid database to retrieve generic HRQoL instruments [11]. Among the 129 generic instruments found, 87 were excluded because they were not HRQoL instruments, were infrequently used (i.e., had fewer than five references), or their target group was not adults. In addition, 12 tools were excluded because they were limited to certain specific dimensions, general quality of life measures, or consisted of open questions. We included another four HRQoL instruments developed in Korea, Japan, China, and France that were identified in a separate search. Ultimately, $34 \mathrm{HRQ}$ oL instruments were selected and their questionnaires were collected. 
A total of 166 items were derived from these $34 \mathrm{HRQ}$ oL instruments. From the 166 items, we excluded three items which were specific to a particular gender or age group (being a parent, fertility, and studying), 48 items that overlapped with other items (e.g., walking vs. getting around and bending or stooping vs. picking up something from the floor), two items that were difficult to differentiate because they dealt with similar concepts (e.g., confidence vs. self-efficacy), and 44 items that were related to general quality of life or were considered less important than other items for measuring HRQoL. Although redundant or overlapping items were excluded, we retained items that were regarded as meaningful in the Korean context (e.g., vitality, fatigue, and fatigue recovery). Ultimately, we selected 69 items for focus group discussion (FGD), indepth interviews (IDIs), and expert consultations.

\section{Focus Group Discussion, In-depth Interviews, and Expert Consultations for the First Item Re- duction}

FGD and IDIs were conducted to collect qualitative data on various perceptions of health and HRQoL and to select candidate items according to semi-structured guidelines (Supplemental Table 1). The focus group consisted of six healthy adults chosen on the basis of gender and age (three women; mean age, 40 years). The IDIs were conducted with six chronically ill adults with mild symptoms who were recruited from the outpatient Department of Family Medicine in a tertiary general hospital (four women; mean age, 59 years). They each had some combination of diabetes mellitus, Parkinson disease, hypercholesterolemia, hypertension, or anemia. Openended questions were asked, such as "When do you think you are healthy or not healthy?" and "What do you think are the dimensions that belong to HRQoL?". Next, we presented 69 items retrieved from the $34 \mathrm{HRQ}$ L instruments identified in the previous step of our procedure and asked the participants to select important HRQoL items. The transcripts of the FGD and IDIs were analyzed using content analysis. The participants of FGD and IDIs selected the items in the mental and positive health dimension, such as happiness, joy, and positive feelings/thinking, as the most important HRQoL items. The methods and results of the FGD and IDIs have been described in more detail elsewhere [22]. Experts who had developed HRQoL instruments or used HRQoL instruments frequently were considered for expert consultation. Academic societies on health technology assessment, statistics, family medicine, and psychology proposed experts who engaged in research on HRQoL and HRQoL instruments. Consultations with 11 experts were held to obtain opinions about HRQoL dimensions, item generation and selection, levels of items, and the recall period, as well as to ask the same questions used in the FGD and IDIs. The experts proposed using a 4-point Likert scale to record responses, the past week as the recall period, past tense corresponding to the recall period, and a new item (building relationships with new people). Using the FGD, IDIs, and expert consultations, we identified 30 items, including six pairs of items measured in terms of intensity and frequency: fatigue, loneliness, depression, satisfaction, confidence, and happiness. Each item consisted of four levels with the following options: no difficulty, some difficulty, much difficulty, or unable; no, mild, severe, or extreme; and always, often, occasionally, or never. Level 1 corresponded to having no problem and level 4 corresponded to having an extremely severe problem for each item.

\section{Surveys}

\section{Study population}

Two surveys were conducted as part of the present study (Figure 1). The first survey was conducted for the second round of item reduction and the second survey was conducted to examine the validity and reliability of the instrument. The target population was adults over 19 years old in Korea. In the first survey for the second round of item reduction, 891 adults participated. Of the 891 participants, 600 were randomly sampled using the multistage stratified quota method. We assigned a sample quota to each region of Korea according to the popula-

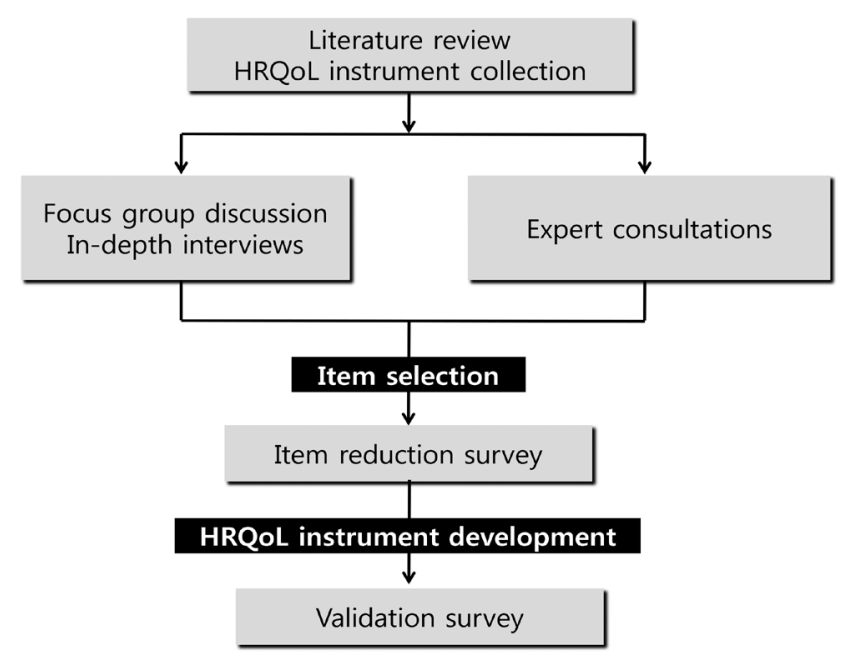

Figure 1. Study flow. HRQoL, health-related quality of life. 
tion structure based on gender, age, and education level, derived from the resident registration data (June 2014) of the Korean Ministry of Interior. To increase the sample size, we included 291 adults participating in the sixth Korea National Health and Nutrition Examination Survey (KNHANES). They were asked to complete a questionnaire that included general characteristics, such as gender, age, and education level, and the 30 candidate items. In the second survey that was conducted to validate the instrument, 300 adults in Seoul, Gyeonggi-do, and Incheon, Korea were randomly selected according to the multistage stratified quota method by gender and age. Of them, 100 adults who consented to retest participated in the retest survey after 7-14 days. Surveys were mainly self-administered or were carried out with the partial assistance of trained interviewers. Before participating in the surveys, all respondents provided informed consent. Ethical approval to conduct these surveys was received from the institutional review board of Asan Medical Center (S2014-1376-0001).

\section{Second item reduction: Health-related Quality of Life In- strument with 20 items development}

After the first survey, we examined the percentage of respondents who selected each answer choice for each item. Exploratory factor analysis (EFA) with principal components analysis and varimax rotation was carried out to identify the underlying structure of the data. Eigenvalues $>1$ were used to determine the number of retaining factors. Confirmatory factor analysis (CFA) was conducted to test the structure based on EFA. To test the goodness of fit of the model, the following statistical indicators [23] were used: the goodness-of-fit index (GFl; with a cutoff of $>0.9$ ); the comparative fit index (CFl; with a cutoff of $>0.9$ ); the Tucker-Lewis index (TLl; with a cutoff of $>0.9$ ); and the root mean square error of approximation (RMSEA; with a cutoff of $<0.08$ ). The convergent validity and discriminant validity of the factor structure were assessed by several criteria [24]. Convergent validity was confirmed by factor loading ( $>0.5$ ), average variance extracted (AVE; values $>0.7$ considered to be very good), and composite reliability (CR; values $>0.7$ considered to be acceptable). Discriminant validity was defined as the presence of an AVE greater than the interfactor squared correlation.

Based on the results of these statistical analyses, we selected a final panel of 20 items for our novel instrument (HINT-20). The Korean-language implementation of the HINT-20 questionnaire was supervised by the National Institute of the Kore- an Language (Supplemental Figure 1 for the English version and Supplemental Figure 2 for the Korean version of the HINT20). The scoring of the HINT-20 is presented in Supplemental Figure 3. The total score of the HINT-20 is converted to a $0-100$ scale, with higher scores indicating better HRQoL.

\section{Validity and reliability of the Health-related Quality of Life Instrument with 20 items}

To demonstrate known-groups validity for the HINT-20, we calculated total HINT-20 scores. It was assumed that the total HINT-20 scores would be higher in men, young people, and those in higher income groups. The total HINT-20 score would correlate positively with monthly household income and negatively with age. To confirm convergent validity, a higher correlation should be demonstrated between items in the physical health dimension and the physical component summary (PCS) of the SF-36v2 and between items in the mental health dimension and mental component summary (MCS) of the SF$36 \mathrm{v} 2$ than across categories. Discriminant validity would be supported by lower correlations between the items in physical health dimension and the MCS and between items in the mental health dimension and the PCS. For this purpose, Spearman correlations were used. Test-retest reliability was assessed using the Cohen kappa value, the agreement rate, and the intraclass correlation coefficient (ICC). All ICCs were 2-way random single measures with absolute agreement. Internal consistency was measured using Cronbach alpha values.

\section{Statistical Analysis}

We used SPSS version 21 (IBM Corp., Armonk, NY, USA) to perform all statistical analyses, AMOS 22 (IBM Corp., Chicago, IL, USA) to carry out CFA, and Quality Metric Health Outcomes Scoring version 4.5 (QualityMetric Inc., Lincoln, RI, USA) to calculate scales and component summaries of the SF-36v2.

\section{RESULTS}

\section{General Characteristics of the Survey Partici- pants}

The socio-demographic characteristics of the survey respondents are presented in Table 1. The number of respondents was 891 in the survey for item reduction (first survey). In the second survey, 300 adults participated to examine validity, of whom 100 respondents participated in the retest to examine reliability. The mean age of the respondents who participated 
Table 1. Socio-demographic characteristics of the respondents

\begin{tabular}{|c|c|c|c|}
\hline \multirow{2}{*}{ Characteristics } & \multirow{2}{*}{$\begin{array}{l}\text { Survey for item } \\
\text { reduction } \\
(\mathbf{n}=891)^{1}\end{array}$} & \multicolumn{2}{|c|}{$\begin{array}{c}\text { Survey for testing validity } \\
\text { and reliability }\end{array}$} \\
\hline & & $\begin{array}{c}\text { Subject } \\
(\mathrm{n}=300)^{2}\end{array}$ & $\begin{array}{c}\text { Subject } \\
(\mathrm{n}=100)^{3}\end{array}$ \\
\hline \multicolumn{4}{|l|}{ Gender } \\
\hline Women & 476 (53.4) & $151(50.3)$ & $52(52.0)$ \\
\hline Men & $415(46.6)$ & $149(49.7)$ & $48(48.0)$ \\
\hline \multicolumn{4}{|l|}{ Age (y) } \\
\hline Mean $\pm S D$ & $47.0 \pm 14.8$ & $44.6 \pm 13.2$ & $45.1 \pm 13.3$ \\
\hline $19-29$ & 142 (15.9) & 56 (18.7) & $18(18.0)$ \\
\hline $30-39$ & $153(17.2)$ & $62(20.7)$ & $20(20.0)$ \\
\hline $40-49$ & $183(20.5)$ & $68(22.7)$ & $22(22.0)$ \\
\hline $50-59$ & $192(21.5)$ & $57(19.0)$ & $20(20.0)$ \\
\hline$\geq 60$ & $221(24.8)$ & $57(19.0)$ & $20(20.0)$ \\
\hline \multicolumn{4}{|c|}{ Education duration (y) } \\
\hline$\leq 9$ & $160(18.3)$ & $27(9.0)$ & $9(9.0)$ \\
\hline $10-12$ & $315(36.0)$ & $127(42.3)$ & $45(45.0)$ \\
\hline$\geq 13$ & $399(45.7)$ & $146(48.7)$ & $46(46.0)$ \\
\hline \multicolumn{4}{|l|}{ Marital status } \\
\hline Single & $192(21.6)$ & $68(22.7)$ & $20(20.0)$ \\
\hline Married & $623(70.0)$ & $222(74.0)$ & $76(76.0)$ \\
\hline Other ${ }^{4}$ & $75(8.4)$ & $10(3.3)$ & $4(4.0)$ \\
\hline \multicolumn{4}{|l|}{$\begin{array}{l}\text { Monthly household } \\
\text { income }\end{array}$} \\
\hline 1st quartile & $204(24.8)$ & $63(22.7)$ & $17(18.5)$ \\
\hline 2nd quartile & $196(23.9)$ & $72(25.9)$ & $24(26.1)$ \\
\hline 3rd quartile & $212(25.8)$ & $72(25.9)$ & $27(29.3)$ \\
\hline 4th quartile & $209(25.5)$ & $71(25.5)$ & $24(26.1)$ \\
\hline
\end{tabular}

Values are presented as number (\%).

SD, standard deviation.

${ }^{1} T$ The subjects consisted of 600 individuals who were sampled nationwide according to the population structure and 291 who participated in the sixth Korea National Health and Nutrition Examination Survey.

${ }^{2}$ The subjects were sampled in Seoul, Gyeonggi-do, and Incheon.

${ }^{3}$ The subjects were a subset of those who participated in the validity survey.

${ }^{4}$ Divorced, widowed, or unknown.

in the first and second surveys and the retest was 47.0 years (standard deviation [SD], 14.8), 44.6 years (SD, 13.2), and 45.1 years (SD, 13.3), respectively. The proportion of female respondents $(53.4,50.3$, and $52.0 \%$, respectively) was higher than that of male respondents. Most participants had completed more than 10 years of education $(81.7,91.0$, and $91.0 \%$, respectively) and were married (70.0, 74.0, and $76.0 \%$, respectively). The majority of participants had not used ambulatory care services in the past two weeks $(76.0 \%$ in the first survey and $82.0 \%$ in the second survey for validity) and had not been admitted to a hospital in the last year ( $98.5 \%$ in the first survey and $96.3 \%$ in the second survey for validity).
Second Item Reduction: Health-related Quality of Life Instrument With 20 Items Development

In the first survey, 92.5 to $98.0 \%$ of respondents selected the response option corresponding to level 1 , which meant they had no problem, in four items: eating without someone's help, toileting, hearing, and speaking. Accordingly, we excluded these items with high ceiling effect described as a large proportion of no problem response in each item, as we thought they would not be able to discriminate between different groups; this decision was also supported by experts' opinions. We then performed EFA of the remaining 26 items. EFA identified six factors with eigenvalues $>1$ that explained $70.4 \%$ of the total variance in the data. The factors corresponded to four previously described health dimensions. Factors 2 and 5 corresponded to the physical health dimension, factor 4 to the social health dimension, factors 3 and 6 to the mental health dimension, and factor 1 to the positive health dimension (Table 2). Three items showed crossed loadings in different factors: seeing (factors 2 and 6), working (factors 2 and 4), and sleep (factors 3 and 6 ). These items were assigned to the factor with the highest loading. Based on the results of the EFA, the 26 items with six factors (model 1) underwent CFA. The goodness of fit of model 1 was unsatisfactory (GFI, $0.85 ; \mathrm{CFI}, 0.89 ; \mathrm{TLI}, 0.87$; and RMSEA, 0.08). The convergent validity of model 1 was acceptable, with almost all items demonstrating factor loadings $>0.5$, except the seeing item (0.498), and AVEs and CRs $>0.7$ for all factors. In terms of the discriminant validity of model 1, the AVEs were greater than all interfactor squared correlations. In an attempt to improve the model fit, model 2, containing 20 items, was hypothesized. We decided to exclude six items expressed as intensity from the six pairs of items from model 1 , because the correlations between items represented by intensity and frequency were high (Spearman rho, 0.717 to 0.888 ; $p<0.01$ ) and items such as happiness, confidence, and satisfaction could be easily understood from the expressions of frequency. Model 2 with 20 items, which retained the 6-factor structure of model 1 , was assessed by CFA. The goodness of fit of model 2 was more acceptable than that of model 1 (GFI, 0.92; CFI, 0.92; TLI, 0.91; and RMSEA, 0.07). Model 2 demonstrated acceptable factor loadings $(>0.5)$ except for the seeing item (0.50), and AVEs and CRs $>0.7$ for all factors. Model 2 also exhibited discriminant validity between all factors. Model 2 , which was ultimately chosen as our instrument, comprised eight items in the physical health dimension, four items in the social health dimension, five items in the mental health dimen- 
Table 2. Factor loadings of 26 items in the first survey

\begin{tabular}{|c|c|c|c|c|c|c|}
\hline \multirow{2}{*}{ Items } & \multicolumn{6}{|c|}{ Factor coefficients after rotation } \\
\hline & 1 & 2 & 3 & 4 & 5 & 6 \\
\hline Satisfaction ${ }^{1}$ & 0.854 & 0.095 & 0.172 & 0.092 & 0.156 & 0.088 \\
\hline Satisfaction ${ }^{2}$ & 0.842 & 0.102 & 0.196 & 0.111 & 0.112 & 0.076 \\
\hline Confidence $^{1}$ & 0.819 & 0.147 & 0.118 & 0.138 & 0.159 & 0.152 \\
\hline Happiness ${ }^{1}$ & 0.814 & 0.152 & 0.199 & 0.065 & 0.102 & 0.085 \\
\hline Confidence $^{2}$ & 0.753 & 0.122 & 0.150 & 0.172 & 0.159 & 0.155 \\
\hline Happiness² & 0.732 & 0.125 & 0.322 & 0.098 & 0.142 & 0.088 \\
\hline Walking & 0.078 & 0.830 & 0.086 & 0.100 & 0.091 & 0.087 \\
\hline Climbing stairs & 0.104 & 0.794 & 0.050 & 0.072 & 0.094 & 0.203 \\
\hline Symptoms limiting usual activities & 0.135 & 0.788 & 0.142 & 0.120 & 0.106 & 0.047 \\
\hline Doing housework & 0.128 & 0.748 & 0.183 & 0.174 & 0.045 & 0.058 \\
\hline Pain & 0.141 & 0.727 & 0.131 & 0.053 & 0.243 & 0.113 \\
\hline Seeing & 0.091 & 0.478 & 0.06 & -0.043 & 0.118 & 0.385 \\
\hline Loneliness ${ }^{1}$ & 0.275 & 0.106 & 0.816 & 0.171 & 0.074 & 0.106 \\
\hline Depression ${ }^{2}$ & 0.224 & 0.194 & 0.805 & 0.239 & 0.162 & 0.102 \\
\hline Depression ${ }^{1}$ & 0.227 & 0.210 & 0.779 & 0.257 & 0.168 & 0.098 \\
\hline Loneliness ${ }^{2}$ & 0.314 & 0.122 & 0.778 & 0.163 & 0.059 & 0.166 \\
\hline Relationships with people other than family & 0.115 & 0.136 & 0.175 & 0.842 & 0.097 & 0.069 \\
\hline Building relationships with new people & 0.145 & 0.034 & 0.167 & 0.756 & 0.132 & 0.234 \\
\hline Family relationship & 0.198 & 0.182 & 0.302 & 0.686 & 0.046 & 0.039 \\
\hline Working & 0.149 & 0.473 & 0.194 & 0.494 & 0.133 & 0.270 \\
\hline Fatigue $^{2}$ & 0.209 & 0.226 & 0.165 & 0.090 & 0.828 & 0.093 \\
\hline Fatigue $^{1}$ & 0.185 & 0.123 & 0.116 & 0.108 & 0.804 & 0.124 \\
\hline Vitality & 0.350 & 0.269 & 0.111 & 0.148 & 0.589 & 0.091 \\
\hline Concentration & 0.204 & 0.175 & 0.152 & 0.215 & 0.114 & 0.773 \\
\hline Memory & 0.171 & 0.251 & 0.156 & 0.191 & 0.087 & 0.755 \\
\hline Sleep & 0.182 & 0.299 & 0.361 & 0.091 & 0.202 & 0.376 \\
\hline
\end{tabular}

Satisfaction, confidence and happiness loaded onto factor 1; walking, climbing stairs, symptoms limiting usual activities, doing housework, pain, and seeing onto factor 2; Ioneliness and depression onto factor 3; relationships with people other than family, building relationships with new people, family relationship, and working onto factor 4; fatigue and vitality onto factor 5 ; concentration, memory, and sleep onto factor 6 .

${ }^{1}$ Item measured in terms of intensity.

${ }^{2}$ Item measured in terms of frequency.

sion, and three items in the positive health dimension.

\section{Validity and Reliability of Health-related Quality of Life Instrument With 20 Items}

In terms of known-groups validity, the mean total scores of HINT-20 were higher in men, younger people, and higher earners (Table 3). The total score of the HINT-20 correlated positively with monthly household income (Pearson $r=0.229$, $p<0.01$ ) and negatively with age (Pearson $r=-0.552, p<0.01$ ). The items belonging to the physical health dimension, except vitality, had significantly $(p<0.01)$ stronger correlations with the PCS of the SF-36v2 than with the MCS. The items in the social health dimension showed a stronger correlation with the social function scales than with any other scales in the SF$36 \mathrm{v} 2$. The correlation coefficients between items such as depression and loneliness in the mental health dimension and the MCS were significantly higher than between these items and the PCS. All items in the positive health dimension showed stronger correlations with the MCS than with the PCS $(p<0.01)$ (Table 4). In the HINT-20, the kappa values ranged from 0.120 to 0.722 , and all items except for family relationships showed statistically significant findings $(p<0.05)$. The kappa values were low $(<0.2)$ for symptoms limiting usual activities in the physical health dimension and family relationships in the social health dimension. The agreement rates were 62.0 to $88.0 \%$ across all items. The ICCs for the scores of 
Table 3. Mean HINT-20 scores according to the characteristics of the respondents of the second survey

\begin{tabular}{llc}
\hline & Mean (SD) & p-value \\
\hline Gender & & 0.005 \\
Men & $84.1(11.7)$ & \\
Women & $80.0(13.6)$ & $<0.001$ \\
Age (y) & & \\
19-29 & $90.5(7.3)$ & \\
30-39 & $88.4(9.8)$ & \\
40-49 & $83.6(11.1)$ & \\
50-59 & $77.5(9.3)$ & \\
$\geq 60$ & $69.4(13.6)$ & \\
Monthly household income & & \\
1st quartile & $75.3(15.3)$ & \\
2nd quartile & $85.1(10.7)$ & \\
3rd quartile & $83.4(11.5)$ & \\
4th quartile & $84.5(11.0)$ & \\
Education duration (y) & & \\
$\leq 9$ & & \\
10-12 & & \\
$\geq 13$ & $66.7(14.1)$ & \\
Ambulatory care visit in the past & & \\
2 weeks & & \\
Yes & & \\
No & & \\
Hospitalization in the past year & & \\
Yes & & \\
No & & \\
Self-rated health & & \\
Excellent & & \\
Very good & & \\
Good & & \\
Fair & & \\
\hline
\end{tabular}

SD, standard deviation; HINT-20, Health-related Quality of Life Instrument with 20 items.

each dimension and the total score were $>0.7$, except in the social health dimension (Table 5). The Cronbach alpha values for the measurement of internal consistency for the items in each dimension were 0.827 to 0.885 .

\section{DISCUSSION}

Using qualitative and quantitative methods and expert consultations, we developed a novel HRQoL instrument, the HINT20 , to better reflect the views of the general Korean population on health and HRQoL. The current study showed that
HINT-20 was valid and reliable for measuring the HRQoL of the general population in Korea.

This novel instrument included 1 new item (building relationships with new people), and the other items constituted reorganized preexisting items rather than being new items. Although several items in the HINT-20 are similar to those of the SF-36v2, the HINT-20 may be used for more detailed measurements than can be obtained with the SF-36v2, which has just 1 question related to the positive health dimension. The items regarding concentration and memory in the HINT-20 were grouped with sleep rather than with fatigue or vitality in factor 6 of the EFA. Cognitive function is associated not only with fatigue [25], but also with sleep [26]. Moreover, Koreans' sleeping time has been found to be shorter than that of the inhabitants of any other Organization for Economic Cooperation and Development country [27]. The existence of factor 6, dealing with concentration, memory, and sleep, might reflect Korean perspectives on HRQoL.

Of particular note, through the FGD, IDIs, and expert consultations, we attempted to construct the HINT-20 instrument while including the positive dimensions of HRQoL, consisting of happiness, confidence, and satisfaction. Traditionally HRQoL instruments have focused on poor health and performance/ capacity deficits instead of on optimal health status [9]. Moreover, the items in the positive health dimension of HINT-20 seem to more closely reflect general quality of life than HRQoL [28]. To encompass the broad spectrum of HRQoL, positive and negative aspects of health status must be incorporated [29]. Almost half of the aforementioned $34 \mathrm{HRQ}$ oL instruments, such as SF-36v2 and the WHOQOL-BREF [30], include items measuring happiness, confidence, and satisfaction. Different opinions have been proposed regarding HRQoL and happiness. Happiness has been said to be a component of HRQoL by some researchers [31,32], while others have concluded that happiness and HRQoL refer to different aspects of well-being $[33,34]$. Thus, it is not clear whether happiness is a predictor of HRQoL. Previous reports have speculated that happiness may be a determinant of HRQoL [35] or may be predicted by health [36]. In the qualitative research underlying this study, the view was articulated that happiness is an important item for measuring $\mathrm{HRQ}$ oL, which is why we incorporated it as an item measuring $\mathrm{HRQ} \mathrm{L}$, despite the existence of differing views on the relationship between happiness and HRQoL.

The convergent/discriminant validity and reliability of HINT20 were demonstrated, with acceptable results. Items dealing 
Table 4. Correlations between the outcomes of the HINT-20 and SF-36v2 in the second survey

\begin{tabular}{|c|c|c|c|c|c|c|c|c|c|c|}
\hline \multirow{2}{*}{ Items of the HINT-20 ${ }^{1}$} & \multicolumn{10}{|c|}{ SF-36v2 } \\
\hline & PF & $\mathbf{R P}$ & BP & GH & VT & SF & RE & MH & PCS & MCS \\
\hline \multicolumn{11}{|l|}{ Physical health dimension } \\
\hline Walking & 0.423 & 0.445 & 0.442 & 0.380 & 0.366 & 0.484 & 0.411 & 0.396 & 0.440 & 0.397 \\
\hline Climbing stairs & 0.617 & 0.600 & 0.578 & 0.433 & 0.480 & 0.578 & 0.516 & 0.513 & 0.595 & 0.486 \\
\hline Doing housework & 0.528 & 0.609 & 0.579 & 0.420 & 0.441 & 0.587 & 0.548 & 0.435 & 0.575 & 0.460 \\
\hline Seeing & 0.480 & 0.471 & 0.404 & 0.371 & 0.396 & 0.448 & 0.404 & 0.395 & 0.476 & 0.374 \\
\hline Pain & 0.536 & 0.577 & 0.770 & 0.473 & 0.492 & 0.575 & 0.486 & 0.403 & 0.662 & 0.433 \\
\hline \multicolumn{11}{|l|}{ Symptoms } \\
\hline limiting usual activities & 0.493 & 0.637 & 0.683 & 0.483 & 0.470 & 0.611 & 0.540 & 0.343 & 0.643 & 0.428 \\
\hline Vitality & 0.472 & 0.450 & 0.527 & 0.521 & 0.613 & 0.463 & 0.390 & 0.521 & 0.521 & 0.521 \\
\hline Fatigue & 0.469 & 0.411 & 0.493 & 0.504 & 0.559 & 0.459 & 0.357 & 0.468 & 0.515 & 0.482 \\
\hline \multicolumn{11}{|l|}{ Social health dimension } \\
\hline Family relationships & 0.336 & 0.412 & 0.321 & 0.277 & 0.326 & 0.452 & 0.404 & 0.323 & 0.321 & 0.373 \\
\hline $\begin{array}{l}\text { Relationships with people } \\
\text { other than family }\end{array}$ & 0.425 & 0.432 & 0.429 & 0.358 & 0.381 & 0.546 & 0.397 & 0.378 & 0.415 & 0.404 \\
\hline $\begin{array}{l}\text { Building relationships with } \\
\text { new people }\end{array}$ & 0.443 & 0.387 & 0.354 & 0.335 & 0.357 & 0.494 & 0.351 & 0.357 & 0.408 & 0.373 \\
\hline Working & 0.551 & 0.531 & 0.497 & 0.456 & 0.487 & 0.603 & 0.476 & 0.426 & 0.548 & 0.466 \\
\hline \multicolumn{11}{|l|}{ Mental health dimension } \\
\hline Depression & 0.372 & 0.426 & 0.410 & 0.432 & 0.394 & 0.595 & 0.480 & 0.548 & 0.384 & 0.566 \\
\hline Loneliness & 0.296 & 0.381 & 0.316 & 0.318 & 0.247 & 0.470 & 0.427 & 0.494 & 0.264 & 0.473 \\
\hline Memory & 0.499 & 0.479 & 0.430 & 0.312 & 0.391 & 0.445 & 0.387 & 0.244 & 0.504 & 0.316 \\
\hline Concentration & 0.482 & 0.439 & 0.393 & 0.348 & 0.426 & 0.488 & 0.480 & 0.381 & 0.441 & 0.441 \\
\hline Sleep & 0.419 & 0.502 & 0.402 & 0.398 & 0.363 & 0.500 & 0.445 & 0.381 & 0.459 & 0.413 \\
\hline \multicolumn{11}{|l|}{ Positive health dimension } \\
\hline Happiness & 0.278 & 0.327 & 0.343 & 0.485 & 0.452 & 0.402 & 0.299 & 0.524 & 0.348 & 0.500 \\
\hline Confidence & 0.354 & 0.292 & 0.331 & 0.529 & 0.554 & 0.326 & 0.245 & 0.506 & 0.398 & 0.471 \\
\hline Satisfaction & 0.321 & 0.294 & 0.314 & 0.486 & 0.486 & 0.353 & 0.283 & 0.449 & 0.362 & 0.457 \\
\hline Total score of HINT-20² & 0.648 & 0.662 & 0.669 & 0.679 & 0.665 & 0.730 & 0.614 & 0.658 & 0.714 & 0.678 \\
\hline
\end{tabular}

All correlations were significant $(p<0.01)$.

PF, physical functioning; RP, role-physical; BP, bodily pain; GH, general health; VT, vitality; SF, social functioning; RE, role-emotional; MH, mental health; PCS, physical component summary; MCS, mental component summary; HINT-20, Health-related Quality of Life Instrument with 20 Items; SF-36v2, Short Form 36 version 2.

${ }^{1}$ The correlations between the items of the HINT-20 and the scales of the SF-36v2 are expressed as Spearman correlation coefficients.

${ }^{2}$ The correlations between the total score of HINT-20 and the outcomes of the SF-36v2 are expressed as Pearson correlation coefficients.

with physical or social health, such as climbing stairs, pain, and working, had high correlation coefficients with the relevant scales of the SF-36v2 (physical functioning [PF], bodily pain $[\mathrm{BP}]$, and social functioning [SF], respectively), and items assessing mental and positive health, such as depression and happiness, showed high correlations with the MH scale of the SF-36v2. In addition, these items had low correlation coefficients with less relevant scales. The relationships among items of the HINT-20 and SF-36v2 showed better convergent and discriminant validity than those of other preexisting HRQoL instruments, such as the EQ-5D. In an earlier Chinese study [37], the correlation between the PF and mobility of the EQ-5D was reported to be -0.44 , that of PF with usual activity as -0.40 , that of $\mathrm{BP}$ with pain/discomfort as -0.59 , and that of $\mathrm{MH}$ with anxiety/depression as -0.37 (all $p<0.001$ ). Compared with the study, the correlations in our current study were similar or stronger between walking and PF (0.42), doing housework and PF (0.53), pain and BP (0.77), depression and MH (0.55), and loneliness and $\mathrm{MH}(0.49)$ (all $p<0.01$ ). The test-retest agreement rate in the Chinese study was found to be 100.0, 96.8, 74.2, and $93.6 \%$ for mobility, usual activities, pain/discomfort, and anxiety/depression, respectively. In current study, the agreement rates for walking (87.0\%), doing housework $(88.0 \%)$, pain $(85.0 \%)$, and depression (76.0\%) were slightly 
Table 5. Agreement rates and intraclass correlation coefficients (ICC) for test-retest reliability in the second survey $(n=100)$

\begin{tabular}{|c|c|c|}
\hline & $\begin{array}{l}\text { Agreement } \\
\text { rate }(\%)\end{array}$ & ICC** \\
\hline Physical health dimension & & 0.818 \\
\hline Walking & 87.0 & \\
\hline Climbing stairs & 88.0 & \\
\hline Doing housework & 88.0 & \\
\hline Seeing & 88.0 & \\
\hline Pain & 85.0 & \\
\hline Symptoms limiting usual activities & 81.0 & \\
\hline Vitality & 72.0 & \\
\hline Fatigue & 62.0 & \\
\hline Social health dimension & & 0.466 \\
\hline Family relationships & 76.0 & \\
\hline Relationships with people other than family & 75.0 & \\
\hline Building relationships with new people & 75.0 & \\
\hline Working & 83.0 & \\
\hline Mental health dimension & & 0.790 \\
\hline Depression & 76.0 & \\
\hline Loneliness & 79.0 & \\
\hline Memory & 72.0 & \\
\hline Concentration & 79.0 & \\
\hline Sleep & 77.0 & \\
\hline Positive health dimension & & 0.724 \\
\hline Happiness & 65.0 & \\
\hline Confidence & 62.0 & \\
\hline Satisfaction & 64.0 & \\
\hline Total score & & 0.813 \\
\hline
\end{tabular}

lower or higher. The validity of the EQ-5D reported by Kontodimopoulos et al. [38] is similar to that found in the present study. A previous study [39] evaluating the validity and reliability of the EQ-5D-3L and EQ-5D-5L in the Korean general population reported correlations and agreement rates similar to those found in our current study. However, some HINT-20 items, such as vitality and fatigue, showed similarly high correlations with all eight scales of the SF-36v2. This may have been because these factors are affected by both physical and mental health. Castro et al. [40] showed that the environmental domain of the WHOQOL-BREF had similar correlation coefficients with PF $(r=0.32, p<0.001)$ and $\mathrm{MH}(r=0.39, p<0.001)$.

The present study has some notable limitations. First, increasing the sample size by adding additional respondents from the KNHANES in the first survey may have limited the representativeness of the sample. Although the demographic profiles of the respondents were generally similar to those of the Korean general population reported in the 2010 national census, the respondents of the first survey were older and higher-educated, and the number of married respondents in the first and second surveys was greater than in 2010 national census. Additionally, the respondents in this study reported consuming fewer health care services than the respondents of the sixth KNHANES in 2014. This means that the respondents in this study may have been healthier than the general Korean population. The distributions of age, educational level, marital status, and health status in the first survey sample may have influenced the second round of item reduction. Despite adding 291 respondents, we obtained the same results that were obtained with all 891 respondents when analyzing the data of the subset of the 600 respondents who were sampled from the general population. Second, the two surveys conducted in this study included members of the general population, rather than patients. Although qualitative data were collected through IDIs with patients, the HINT-20 was not evaluated in a large patient group. If patient groups were recruited, the validity of this instrument could have had been tested in another setting. Third, the recall period and level (number of response options) were not based on substantial data from the general population, but mainly on expert opinions. The impact of the recall period and level on HRQoL measurements will thus need to be examined in further studies. The fourth limitation was that we did not seek to establish an overall balance among the dimensions, as our analysis was conducted in order to select items for each dimension. Thus, the number of items per dimension was not equal. In addition, since the physical health dimension consists of eight items, this dimension may exert more influence on the score of the HINT-20 than the other health dimensions. Additional studies are needed to collect information that will allow the number of items to be balanced among the four health dimensions. This point should be considered when interpreting HINT-20 scores. Finally, although qualitative methods were used to derive opinions on items and dimensions from a small proportion of the general population, an expansive qualitative approach needs to be considered to accumulate more qualitative data.

In conclusion, a novel self-administered HRQoL instrument, the HINT-20, was developed and was found to be a valid and reliable instrument. The HINT-20 has the advantage of reflecting the perspectives of Koreans and of including a positive 
health dimension, allowing it to encompass a wide spectrum of aspects of HRQoL. The HINT-20 can be used in community and clinical settings to gather sufficient data on HRQoL. Further study is needed to examine the validity and reliability of the HINT-20 in different cultures.

\section{ACKNOWLEDGEMENTS}

This work was supported by the Research Program funded by Korea Centers for Disease Control and Prevention (no. 2014E35008-00).

\section{CONFLICT OF INTEREST}

The authors have no conflicts of interest associated with the material presented in this paper.

\section{ORCID}

Min-Woo Jo http://orcid.org/0000-0002-4574-1318

Hyeon-Jeong Lee http://orcid.org/0000-0002-0822-2420

Soo Young Kim http://orcid.org/0000-0002-3205-9408

Seon-Ha Kim http://orcid.org/0000-0002-9417-396X

Hyejung Chang http://orcid.org/0000-0002-5666-1305

Jeonghoon Ahn http://orcid.org/0000-0002-0177-0192

Minsu Ock http://orcid.org/0000-0001-9949-9224

\section{REFERENCES}

1. Rodríguez-Artalejo F, Guallar-Castillón P, Pascual $C R$, Otero CM, Montes AO, García AN, et al. Health-related quality of life as a predictor of hospital readmission and death among patients with heart failure. Arch Intern Med 2005;165(11):12741279.

2. Otero-Rodríguez A, León-Muñoz LM, Balboa-Castillo T, Banegas JR, Rodríguez-Artalejo F, Guallar-Castillón P. Change in health-related quality of life as a predictor of mortality in the older adults. Qual Life Res 2010;19(1):15-23.

3. van Nooten F, Holmstrom S, Green J, Wiklund I, Odeyemi IA, Wilcox TK. Health economics and outcomes research within drug development: challenges and opportunities for reimbursement and market access within biopharma research. Drug Discov Today 2012;17(11-12):615-622.

4. Gareen IF, Duan F, Greco EM, Snyder BS, Boiselle PM, Park ER, et al. Impact of lung cancer screening results on participant health-related quality of life and state anxiety in the National Lung Screening Trial. Cancer 2014;120(21):3401-3409.

5. Centers for Disease Control and Prevention. Measuring healthy days: population assessment of health-related quality of life; 2000 [cited 2017 Jan 9]. Available from: https://www. cdc.gov/hrqol/pdfs/mhd.pdf.

6. NHS England. Everyone counts: planning for patients 2014/15 2018/19: technical definitions for clinical commissioning groups and area teams [cited 2015 Oct 12]. Available from: https://www.england.nhs.uk/wp-content/uploads/2013/ 12/5yr-strat-plann-guid-wa.pdf.

7. Schipper H, Clinch JJ, Olweny CL. Quality of life studies: definitions and conceptual issues. In: Spilker B, editor. Quality of life and pharmacoeconomics in clinical trials. 2nd ed. Philadelphia: Lippincott-Raven; 1996, p. 11-23.

8. Osoba D. Lessons learned from measuring health-related quality of life in oncology. J Clin Oncol 1994;12(3):608-616.

9. Patrick DL, Erickson P. Health status and health policy: quality of life in health care evaluation and resource allocation. New York: Oxford University Press; 1993, p. 58-64.

10. World Health Organizaion. Constitution of the World Health Organization [cited 2015 Sep 9]. Available from: http://www. who.int/governance/eb/who_constitution_en.pdf.

11. ePROVIDETM. PROQOLID database [cited 2015 Nov 1]. Available from: https://eprovide.mapi-trust.org/search?form[searc hText $]=\&$ form[ezxform_token] =HnJDBAkSIG8hPTmob3480 1cLy0jyub9fShuWYaVyeXY.

12. Szende A, Williams A: EuroQol Group. Measuring self-reported population health : an international perspective based on EQ5D. Budapest: SpringMed Publishing; 2004, p. 27-30.

13. Ock M, Jo MW, Lee SI. Measuring health related quality of life using EQ-5D in South Korea. J Health Tech Assess 2013;1:103111 (Korean).

14. Kang EJ, Ko SK. A catalogue of EQ-5D utility weights for chronic diseases among noninstitutionalized community residents in Korea. Value Health 2009;12 Suppl 3:S114-S117.

15. Johnson JA, Luo N, Shaw JW, Kind P, Coons SJ. Valuations of EQ-5D health states: are the United States and United Kingdom different? Med Care 2005;43(3):221-228.

16. Kim SH, Jo MW, Lee SI. Psychometric properties of the Korean short form-36 health survey version 2 for assessing the general population. Asian Nurs Res (Korean Soc Nurs Sci) 2013; 7(2):61-66.

17. Kim SH, Jo MW, Ahn J, Ock M, Shin S, Park J. Assessment of psychometric properties of the Korean SF-12 v2 in the general 
population. BMC Public Health 2014;14:1086.

18. Wu Y, Xie G. Development and assessment of Chinese general quality of life instrument. In: Preedy VR, Watson RR, editors. Handbook of disease burdens and quality of life measures. New York: Springer; 2010, p. 266-283.

19. Yamaoka K, Hayashi F, Hayashi C, Misumi J, Takezawa S, Maeda $M$, et al. A Japanese version of the questionnaire for quality of life measurement. Ann Cancer Res Ther 1994;3(1):45-53.

20. Kim SY, Shim JY, Won JW, Sun WS, Park HK, Lee JK, The development of Korean health related quality of life scale (KQUOLS): testing reliability and validity. Korean J Fam Med 2000;21(3):382-394 (Korean).

21. Park HJ, Kim S, Bae SC. Current status of health-related quality of life research in Korea. J Korean Rheum Assoc 2002;9(Suppl):S1S17 (Korean).

22. Lee HJ, Ock M, Kim SY, Kim SH, Kim SH, Jo MW. Health group and disease group's perceptions of health and health-related quality of life: a focus group study and in-depth interviews. Korean J Health Promot 2016;16(1):56-66 (Korean).

23. Goursand D, Ferreira MC, Pordeus IA, Mingoti SA, Veiga RT, Paiva SM. Development of a short form of the Brazilian Parental-Caregiver Perceptions Questionnaire using exploratory and confirmatory factor analysis. Qual Life Res 2013;22(2): 393-402.

24. Ghadi I, Alwi NH, Bakar KA, Talib O. Construct validity examination of critical thinking dispositions for undergraduate students in University Putra Malaysia. High Educ Stud 2012;2(2): 138-145.

25. Cull A, Hay C, Love SB, Mackie M, Smets E, Stewart M. What do cancer patients mean when they complain of concentration and memory problems? Br J Cancer 1996;74(10):1674-1679.

26. Curcio G, Ferrara M, De Gennaro L. Sleep loss, learning capacity and academic performance. Sleep Med Rev 2006;10(5): 323-337.

27. Organization for Economic Cooperation and Development. Gender equality: time use across the world [cited $2016 \mathrm{Jul} 17]$. Available from: https://www.oecd.org/gender/data/OECD_ 1564_TUSupdatePortal.xls.

28. Alexandrova A. Subjective well-being and Kahneman's 'objec- tive happiness'. J Happiness Stud 2005;6(3):301-324.

29. Lin XJ, Lin IM, Fan SY. Methodological issues in measuring health-related quality of life. Tzu Chi Med J 2013;25(1):8-12.

30. WHOQOL Group. Development of the World Health Organization WHOQOL-BREF quality of life assessment. Psychol Med 1998;28(3):551-558.

31. Perneger TV, Hudelson PM, Bovier PA. Health and happiness in young Swiss adults. Qual Life Res 2004;13(1):171-178.

32. Sprangers MA, Schwartz CE. Reflections on changeability versus stability of health-related quality of life: distinguishing between its environmental and genetic components. Health Qual Life Outcomes 2008;6:89.

33. Böckerman P, Johansson E, Saarni SI. Do established healthrelated quality-of-life measures adequately capture the impact of chronic conditions on subjective well-being? Health Policy 2011;100(1):91-95.

34. Tessier $P$, Lelorain $S$, Bonnaud-Antignac A. A comparison of the clinical determinants of health-related quality of life and subjective well-being in long-term breast cancer survivors. Eur J Cancer Care (Engl) 2012;21(5):692-700.

35. Robertson SM, Stanley MA, Cully JA, Naik AD. Positive emotional health and diabetes care: concepts, measurement, and clinical implications. Psychosomatics 2012;53(1):1-12.

36. Kozma A, Stones MJ. Predictors of happiness. J Gerontol 1983;38(5):626-628.

37. Wang HM, Patrick DL, Edwards TC, Skalicky AM, Zeng HY, Gu WW. Validation of the EQ-5D in a general population sample in urban China. Qual Life Res 2012;21(1):155-160.

38. Kontodimopoulos N, Pappa E, Niakas D, Yfantopoulos J, Dimitrakaki C, Tountas Y. Validity of the EuroQoL (EQ-5D) instrument in a Greek general population. Value Health 2008;11(7): 1162-1169.

39. Kim TH, Jo MW, Lee SI, Kim SH, Chung SM. Psychometric properties of the EQ-5D-5L in the general population of South Korea. Qual Life Res 2013;22(8):2245-2253.

40. Castro PC, Driusso P, Oishi J. Convergent validity between SF36 and WHOQOL-BREF in older adults. Rev Saude Publica 2014;48(1):63-67. 
Journal of

Preventive Medicine

\& Public Health

Supplemental Table 1. Summary guidelines for conducting focus group discussion and in-depth interviews

Main phases

Opening

Introductory questions

Key questions

\section{Topics}

Explain the procedure and purpose of focus group discussion/in-depth interview

\section{Self-introduction}

Thoughts or feelings about health

One's own past and current health condition

Meaning of health

Meaning of health-related quality of life and its dimensions and items

Selecting important items of health-related quality of life from 69 items

Assessing one's own health-related quality of life using the Euro0ol-5D 


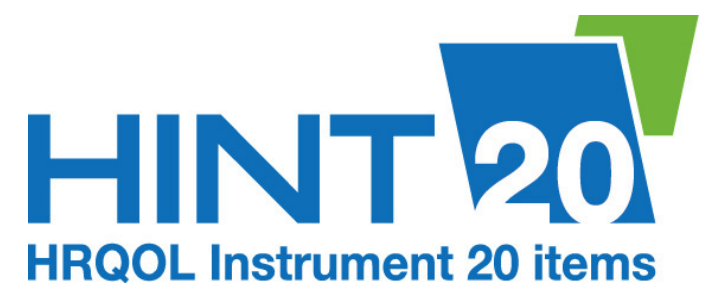

Health-related Quality of Life Instrument with 20 items (HINT-20)

HINT20o is the unique logo of Health-related Quality of Life Instrument with 20 items (HINT-20).

HINT-20 ${ }^{\odot}$ by Korea Centers for Disease Control and Prevention. All rights reserved. 


\section{This questionnaire is about your health during the past 1 week.}

For each question, please choose one answer that is closest to your health status.

I have had no difficulty in walking about.

I have had some difficulty in walking about.

I have had much difficulty in walking about.

I have been unable to walk about.

I have had no difficulty in climbing stairs.

I have had some difficulty in climbing stairs.

I have had much difficulty in climbing stairs.

I have been unable to climb stairs.

I have had no difficulty in doing housework.

$\square \quad$ I have had some difficulty in doing housework.

$\square$ I have had much difficulty in doing housework.

I have been unable to do housework.

I have had no difficulty in seeing.

I have had some difficulty in seeing.

I have had much difficulty in seeing.

I have been unable to see.

\section{This questionnaire is about your health during the past 1 week.} For each question, please choose one answer that is closest to your health status.

\footnotetext{
I have had no pain.

I have had mild pain.

I have had severe pain.

have had extreme pain.
}

have had no symptoms that limit my usual activities.

I have had mild symptoms that limit my usual activities.

I have had severe symptoms that limit my usual activities.

I have had extreme symptoms that limit my usual activities.

I have always been energetic.

$\square$ I have often been energetic.

$\square \quad$ I have occasionally been energetic.

I have never been energetic.

I have never been tired.

$\square \quad$ I have occasionally been tired.

$\square \quad$ I have often been tired.

$\square$ I have always been tired. 


\section{This questionnaire is about your health during the past 1 week.}

For each question, please choose one answer that is closest to your health status.

I have had no difficulty in keeping relationships with my family.
I have had some difficulty in keeping relationships with my family.
I have had much difficulty in keeping relationships with my family.
I have been unable to keep relationships with my family.

I have had no difficulty in keeping relationships with people other than family.

$\square \quad$ I have had some difficulty in keeping relationships with people other than family.

$\square \quad$ I have had much difficulty in keeping relationships with people other than family.

$\square \quad$ I have been unable to keep relationships with people other than family.

I have had no difficulty in building relationships with new people.

$\square \quad$ I have had some difficulty in building relationships with new people.

$\square \quad$ I have had much difficulty in building relationships with new people.

$\square \quad$ I have been unable to build relationships with new people.

I have had no difficulty in working.

$\square \quad$ I have had some difficulty in working.

$\square \quad$ I have had much difficulty in working.

$\square \quad$ I have been unable to work. 


\section{This questionnaire is about your health during the past 1 week.}

For each question, please choose one answer that is closest to your health status.

I have never been depressed.

I have occasionally been depressed.

I have often been depressed.

I have always been depressed.

I have never felt lonely.

I have occasionally felt lonely.

I have often felt lonely.

I have always felt lonely.

I have had no difficulty with memory.

I have had some difficulty with memory.

I have had much difficulty with memory.

I have been unable to memorize.

I have had no difficulty with concentration.

I have had some difficulty with concentration.

I have had much difficulty with concentration.

I have been unable to concentrate.

\section{This questionnaire is about your health during the past 1 week.}

For each question, please choose one answer that is closest to your health status.

I have always been happy.

I have often been happy.

I have occasionally been happy.

I have never been happy.

I have always been confident.

I have often been confident.

I have occasionally been confident.

I have never been confident.

I have always been satisfied with myself and my life.

I have often been satisfied with myself and my life.

I have occasionally been satisfied with myself and my life.

I have never been satisfied with myself and my life. 


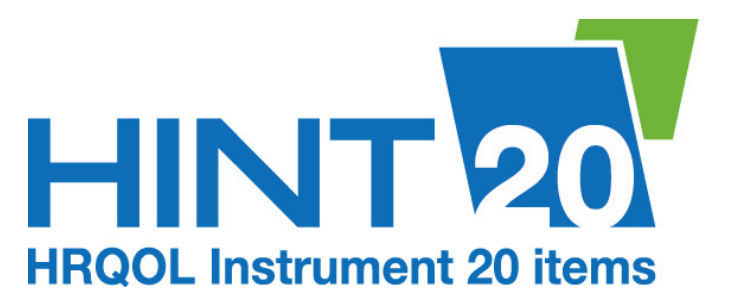

건강관련 삶의 질 측정 도구 (HINT-20)

Health-related Quality of Life Instrument with 20 items

$\underset{\text { HRootinstrument } 20 \text { o toms }}{\mathrm{HINT}}$ 은 "Health-related Quality of Life Instrument with 20 items (HINT-20)" 의 HINT-20 ${ }^{\circ}$ by Korea Centers for Disease Control and Prevention. All rights reserved. 


\section{지난 1주일 동안 귀하의 \\ 건강과 관련된 질문입니다. \\ 보기를 읽고 귀하의 상태를 가장 잘 표현하는 것을 선택하여 주십시오.}

\section{지난 1 주일 동안 귀하의 \\ 건강과 관련된 질문입니다. \\ 보기를 읽고 귀하의 상태를 가장 잘 표현하는 것을 선택하여 주십시오.}

$\square$ 나는 걷는 데 어려움이 전혀 없었다.

$\square$ 나는 걷는 데 어려움이 약간 있었다.

$\square$ 나는 걷는 데 어려움이 많이 있었다.

$\square$ 나는 걸을 수 없었다.

$\square$ 나는 계단을 오르는 데 어려움이 전혀 없었다.

$\square$ 나는 계단을 오르는 데 어려움이 약간 있었다.

$\square$ 나는 계단을 오르는 데 어려움이 많이 있었다.

$\square$ 나는 계단을 오를 수 없었다.

$\square$ 나는 집안일을 하는 데 어려움이 전혀 없었다.

$\square$ 나는 집안일을 하는 데 어려움이 약간 있었다.

$\square$ 나는 집안일을 하는 데 어려움이 많이 있었다.

$\square$ 나는 집안일을 할 수 없었다.

$\square$ 나는 보는 데 어려움이 전혀 없었다.

$\square$ 나는 보는 데 어려움이 약간 있었다.

$\square$ 나는 보는 데 어려움이 많이 있었다.

$\square$ 나는 볼 수 없었다. $\square$ 나는 전혀 통증이 없었다.

$\square$ 나는 약한 통증이 있었다.

$\square$ 나는 심한 통증이 있었다.

$\square$ 나는 극심한 통증이 있었다.

$\square$ 나는 일상 활동을 제한하는 증상이 전혀 없었다.

$\square$ 나는 일상 활동을 제한하는 증상이 약하게 있었다.

$\square$ 나는 일상 활동을 제한하는 증상이 심하게 있었다.

$\square$ 나는 일상 활동을 제한하는 증상이 극심하게 있었다.

$\square$ 나는 항상 기운이 있었다.

$\square$ 나는 자주 기운이 있었다.

$\square$ 나는 가끔 기운이 있었다.

$\square$ 나는 전혀 기운이 없었다.

$\square$ 나는 전혀 피곤하지 않았다.

$\square$ 나는 가끔 피곤했다.

$\square$ 나는 자주 피곤했다.

$\square$ 나는 항상 피곤했다. 


\section{지난 1 주일 동안 귀하의 건강과 관련된 질문입니다. 보기를 읽고 귀하의 상태를 가장 잘 표현하는 것을 선택하여 주십시오.}

나는 가족과의 관계를 유지하는 데 어려움이 전혀 없었다.

$\square$ 나는 가족과의 관계를 유지하는 데 어려움이 약간 있었다.

$\square$ 나는 가족과의 관계를 유지하는 데 어려움이 많이 있었다.

$\square$ 나는 가족과의 관계를 유지할 수 없었다.

나는 가족 이외의 다른 사람들과 관계를 유지하는 데 어려움이 전혀 없었다.

$\square$ 나는 가족 이외의 다른 사람들과 관계를 유지하는 데 어려움이 약간 있었다.

$\square$ 나는 가족 이외의 다른 사람들과 관계를 유지하는 데 어려움이 많이 있었다.

$\square$ 나는 가족 이외의 다른 사람들과 관계를 유지할 수 없었다.

$\square$ 나는 새로운 사람과 관계를 맺는 데 어려움이 전혀 없었다.

$\square$ 나는 새로운 사람과 관계를 맺는 데 어려움이 약간 있었다.

$\square$ 나는 새로운 사람과 관계를 맺는 데 어려움이 많이 있었다.

$\square$ 나는 새로운 사람과 관계를 맺을 수 없었다.

$\square$ 나는 일을 하는 데 어려움이 전혀 없었다.

$\square$ 나는 일을 하는 데 어려움이 약간 있었다.

$\square$ 나는 일을 하는 데 어려움이 많이 있었다.

$\square$ 나는 일을 할 수 없었다. 


\section{지난 1 주일 동안 귀하의 \\ 건강과 관련된 질문입니다. \\ 보기를 읽고 귀하의 상태를 가장 잘 표현하는 것을 선택하여 주십시오.}

\section{지난 1주일 동안 귀하의 \\ 건강과 관련된 질문입니다. \\ 보기를 읽고 귀하의 상태를 가장 잘 표현하는 것을 선택하여 주십시오.}

나는 전혀 우울하지 않았다.

나는 잠을 자는 데 어려움이 전혀 없었다.

나는 가끔 우울했다.

나는 잠을 자는 데 어려움이 약간 있었다.

나는 자주 우울했다.

나는 잠을 자는 데 어려움이 많이 있었다.

$\square$ 나는 항상 우울했다.

$\square$ 나는 잠을 잘 수 없었다.

나는 전혀 외롭지 않았다.

$\square$ 나는 항상 행복했다.

나는 가끔 외로웠다.

$\square$ 나는 자주 행복했다.

$\square$ 나는 자주 외로웠다.

$\square$ 나는 가끔 행복했다.

나는 항상 외로웠다.

나는 전혀 행복하지 않았다.

나는 기억하는 데 어려움이 전혀 없었다.

나는 항상 자신감이 있었다.

나는 기억하는 데 어려움이 약간 있었다.

나는 자주 자신감이 있었다.

$\square$ 나는 기억하는 데 어려움이 많이 있었다.

$\square$ 나는 가끔 자신감이 있었다.

$\square$ 나는 전혀 기억을 할 수 없었다.

$\square$ 나는 전혀 자신감이 없었다.

$\square$ 나는 집중하는 데 어려움이 전혀 없었다.

$\square$ 나는 내 자신과 인생에 대해 항상 만족했다.

$\square$ 나는 집중하는 데 어려움이 약간 있었다.

$\square$ 나는 내 자신과 인생에 대해 자주 만족했다.

$\square$ 나는 집중하는 데 어려움이 많이 있었다.

나는 내 자신과 인생에 대해 가끔 만족했다.

나는 집중할 수 없었다.

나는 내 자신과 인생에 대해 전혀 만족하지 않았다. 
Supplemental Figure 3. Scoring manual of the Health-related Quality of Life Instrument with 20 Items (HINT-20).

The HINT-20 is a novel generic health-related quality of life measurement instrument using a 4-point Likert scale and 1-week recall period. It consists of 4 health dimensions and 20 items.

- Physical health dimension (8 items)

- Walking

- Climbing stairs

- Doing housework

- Seeing

- Pain

- Symptoms limiting usual activities

- Vitality

- Fatigue

- Social health dimension (4 items)

- Family relationships

- Relationships with people other than family

- Building relationships with new people

- Working

- Mental health dimension (5 items)

- Depression

- Loneliness

- Memory

- Concentration

- Sleep

- Positive health dimension (3 items)

- Happiness

- Confidence

- Satisfaction

\section{First step: coding data and recoding data to a raw score}

The first step begins with coding data and converting the data to a raw score. As shown below, the coding method differs according to the 4 types of response options. The 20 items of the HINT-20 each belong to 1 of the 4 types. Each item receives a raw score from 1 to 4 points: 4 points means that no problem is present, whereas 1 point means an extremely severe problem. See the following descriptions.

\section{Type A}

- Walking

- Climbing stairs

- Doing housework

- Seeing

- Relationships with family

- Relationships with people other than family

- Relationships with new people

- Working

- Memory

- Concentration

- Sleep

\begin{tabular}{lcc}
\hline Response options & Coding & Raw score \\
\hline No difficulty & 1 & 4 \\
Some difficulty & 2 & 3 \\
Much difficulty & 3 & 2 \\
Unable & 4 & 1 \\
\hline
\end{tabular}

\section{Type B}

- Pain

- Symptoms limiting usual activities

\begin{tabular}{lcc}
\hline Response options & Coding & Raw score \\
\hline No & 1 & 4 \\
Mild & 2 & 3 \\
Severe & 3 & 2 \\
Extreme & 4 & 1 \\
\hline
\end{tabular}




\begin{tabular}{llc|}
\hline Type C & \\
- Vitality \\
- Happiness \\
- Confidence \\
- Satisfaction & & \\
\hline Response options & Coding & \\
\hline Always & 1 & Raw score \\
Often & 2 & 4 \\
Occasionally & 3 & 3 \\
Never & 4 & 2 \\
\hline
\end{tabular}

\section{Type D}

- Fatigue

- Depression

- Loneliness

\begin{tabular}{lcc}
\hline Response options & Coding & Raw score \\
\hline Never & 1 & 4 \\
Occasionally & 2 & 3 \\
Often & 3 & 2 \\
Always & 4 & 1 \\
\hline
\end{tabular}

\section{Second step: calculating the raw score}

The next step is to calculate the sum of all items included in each dimension. In this process, 4 raw dimensional scores and a total raw score of the HINT-20 are obtained. The maximum and minimum scores of the 4 dimensions are different. See the following descriptions.

\begin{tabular}{lcc}
\hline Health dimension & Minimum raw score & Maximum raw score \\
\hline Physical & 8 & 32 \\
Social & 4 & 16 \\
Mental & 5 & 20 \\
Positive & 3 & 12 \\
Total & 20 & 80 \\
\hline
\end{tabular}

Third step: linear transformation

The total raw score of the HINT-20 calculated in the previous step is converted to a 0-100 scale using the following equation:

$S_{T}=\left(\frac{S_{R}-20}{80-20}\right) \times 100$

$S_{T}$ : total transformed score

SR: total raw score

Fourth step: interpretation

Higher scores in the HINT-20 indicate better HROOL. Care should be taken when interpreting the transformed total score because the physical dimension comprises 8 of the 20 items. 